\title{
LA INDEPENDENCIA JUDICIAL Y SU ENDÉMICO DÉFICIT DE GARANTIIAS
}

\section{JUDICIAL INDEPENDENCE AND ITS ENDEMIC SHORTAGE OF GUARANTEES}

\author{
Perfecto Andrés lbáñez \\ Magistrado emérito del Tribunal Supremo
}

Cómo citar / Nola aipatu: Andrés Ibañez, P. (2021). La independencia judicial y su endémico déficit de garantías. Legebiltzarreko Aldizkaria - LEGAL - Revista del Parlamento Vasco, 2: 8-33

https://doi.org/10.47984/legal.2021.001

\section{RESUMEN}

La independencia judicial es un valor a cuyo dilatado proceso de formación histórica han contribuido la experiencia práctica y la elaboración teórica, siempre en estrecha conflictual relación. En este trabajo se deja breve constancia de ese proceso, contemplando ambas vertientes del asunto. Luego se examina críticamente el modelo napoleónico de organización judicial, un verdadero hito, extraordinariamente difundido y particularmente negativo desde el punto de vista del principio que se considera, que además ha dejado su impronta en todas las organizaciones judiciales de procedencia europea continental. Se presta atención al dato sumamente significativo de la fácil integración funcional de los jueces de ese perfil en la experiencia europea de los nazifascismos y en otras dictaduras. Se discurre sobre las exigencias que el vigente constitucionalismo de derechos suscita en materia de modelo de juez y de estatuto judicial. Y, en fin, se pone el foco en la desoladora experiencia española del Consejo General del Poder Judicial.

\section{PALABRAS CLAVE}

Juez, independencia judicial, carrera judicial, estatuto judicial, estado constitucional de derecho, Consejo General del Poder Judicial.

\section{ABSTRACT}

Practical experience and theoretical elaboration (always in a close conflict relationship) have contributed to the long process of historical development of the value of judicial independence. This paper briefly presents this process considering both aspects of the matter. The author also analyses critically the napoleonic model of judicial organisation, a real landmark, extraordinarily widespread and particularly negative from the point of view of judicial independence, which has left its imprint on all judicial organisations in continental Europe. The paper pays attention to the extremely significant fact of the easy functional integration of judges with this profile in the European experience of nazism and fascism. The writer also reflects on the requirements imposed by the 
current constitutionalism based on rights on the judicial role model and the judicial status. Finally, the paper focuses on the distressing Spanish experience concerning the General Council for the Judiciary.

\section{KEYWORDS}

Judge, judicial independence, judicial career, judiciary Statute, rule of law, General Council of the Judiciary.

\section{LABURPENA}

Independentzia judizialaren balioaren eratze historikoaren prozesu luzean esperientzia praktikoa eta lantze teorikoa, betiere harreman gatazkatsu estuan, lagungarriak izan dira. Lan honetan prozesu horren berri ematen da labur-labur, gaiaren alde biak kontuan hartuz. Ondoren, azterketa kritikoa egiten zaio antolaketa judizialaren eredu napoleonikoari, benetako mugarria hura, izugarri hedatua eta bereziki negatiboa dena aztergai dugun printzipioaren ikuspegitik, gainera, Europa kontinentaleko jatorria duten erakunde judizial guztietan bere arrastoa utzi duena. Arreta jartzen zaio profil horretako epaileek nazismoaren eta faszismoaren zein beste diktaduren Europako esperientzian izan duten integrazio funtzional errazaren datu guztiz esanguratsuari. Eskubideetan oinarritutako konstituzionalismoak, egun indarrean dagoenak, epaile-ereduan eta estatutu judizialaren arloan sortzen dituen eskakizunei buruzko gogoeta egiten da. Eta, azkenik, arreta jartzen du Botere Judizialaren Kontseilu Nagusiaren esperientzia espainiar samingarrian.

\section{GAKO-HITZAK}

Epailea, independentzia judiziala, karrera judiziala, estatutu judiziala, zuzenbidezko estatu konstituzionala, Botere Judizialaren Kontseilu Nagusia.

\section{SUMARIO}

I. PRELIMINAR.

II. BREVE APUNTE HISTÓRICO.

III. LA ELABORACIÓN TEÓRICA.

IV. CARRERA JUDICIAL: EL PROBLEMÁTICO MODELO A LA VISTA DE LOS HECHOS.

V. HACIA UN CAMBIO DE MODELO.

VI. CONSTITUCIONALISMO DE DERECHOS Y MODELO DE JUEZ.

VII. INDEPENDENCIA: REQUERIMIENTOS EN MATERIA DE ESTATUTO JUDICIAL.

VIII. LA DESOLADORA EXPERIENCIA ESPAÑOLA ACTUAL. BIBLIOGRAFÍA. 
Kelsen (2003: 53) lo expresó de manera sumamente sencilla: en origen "hubo (...) solo jurisdicción”. Y esto es algo que muy bien puede predicarse de cualquier grupo humano mínimamente organizado que, por lo general, contará con alguna instancia (institucional en el más amplio sentido), investida de cierta legitimidad y de la autoridad necesaria para dirimir los conflictos entre los asociados, con referencia a alguna clase de normas. Al respecto, cabría hablar de una constante, de una especie de universal.

Seguramente, otro universal es el constituido por la recurrencia de una atávica desconfianza hacia el uso del poder que se expresa en el ejercicio de esta función, en un marco de inevitable, a veces enorme discrecionalidad. Se trata de una actitud con manifestaciones históricas tan expresivas como la representada por el régimen de las ordalías y el de la prueba legal que le siguió. En efecto, pues sin duda, es la que, dando por cierta la existencia de un ser superior providente, debió animar la pretensión de llamarle en causa (nunca mejor dicho) para trasladarle la responsabilidad del juicio, por su presumible interés en el desarrollo de los asuntos humanos, el de la justicia en particular, vista su relevancia. Y otro tanto cabe decir del segundo régimen aludido, fundado en la previa atribución de un valor convictivo fijo a lo aportado por cada medio probatorio, con objeto de dotar de una seguridad tendencialmente objetiva a los criterios de decisión, puenteando, diríamos hoy, al juzgador.

Las aludidas cautelas tienen sobrado fundamento, tratándose de ese poder "tan terrible para los hombres" en el bien fundado concepto de Montesquieu (1972: 152); que, por eso, vendría a imprimir en quien lo encarna una, cabría decir, natural arrogancia. Lo propio, en cierto modo, del cometido consistente en dar y quitar la razón, inevitablemente sugestivo de que el encargado de hacerlo es porque la tendría, toda y en todo caso. Por eso, tal endémica desconfianza, habría desembocado ya tempranamente en una asimismo histórica demanda de garantías para los justiciables. Una exigencia que ocupa un lugar central en la experiencia histórica de la jurisdicción y en la reflexión en torno a ella, en la que el valor independencia tiene asignado un papel de particular relevancia.

Luigi Ferrajoli (2011: 832-833) -en la que, seguramente, es la caracterización más acabada y precisa del (hoy) poder judicial y su función como instancia en el estado constitucional y el actual constitucionalismo- lo concibe como el aparato institucional encargado de cumplir la función de garantía consistente en el desarrollo de una actividad cognoscitiva, de enjuiciamiento, dirigida a la constatación de un acto inválido o de un acto ilícito que pudiera haberse producido, disponiendo en tal caso su anulación o su condena, con declaración y atribución de las correspondientes responsabilidades, todo en aplicación de las normas violadas.

Entre aquel aludido primer momento de la más precaria configuración del instituto de que se trata, y el representado por su actual significación en la geografía estatal y por la profundización conceptual de su tratamiento que acredita la definición que 
acaba de recogerse, hay un decurso de siglos y un permanente entrelazarse de los dos planos aludidos, el práctico-organizativo y el teórico-cultural, en cierta conflictual interacción, de obligada referencia cuando se trata de entender el sentido del principio que da título a estas páginas.

\section{BREVE APUNTE HISTÓRICO}

1 Acerca de esta figura la obra de Kantorowicz (2012) es una referencia obligada. Entre nosotros, también García Pelayo (1968).

2 Este incipiente proceso de conformación de una instancia propiamente jurisdiccional tiene una concreción simbólica en el famoso conflicto del juez Coke con Jacobo I, en la Inglaterra de 1612. Cuando, frente a la pretensión de este-como simple cuestión de poder- de asumir el conocimiento de una causa que, según un régimen de distribución de competencias todavía en formación, no le correspondería, aquel opuso, frente a la potestas, "la razón artificial y el juicio de lo que es el derecho" (Pound, 1954: 73-74).

3 Un excelente tratamiento de esta peculiar institución y de sus vicisitudes, en la literatura española, puede verse en Pardo (2009: 147 y ss.). 
incorporándolo a su patrimonio, que es lo que dio lugar a la anticipación empírica de un cierto apunte de independencia y, con ello, a la emergencia, por esta vía, de una poderosa corporación que acabó asumiendo también algunas funciones polémicas de neta significación política, de limitación o de control del poder real. Tal relevante papel de los Parlamentos, debido a su poder judicial autónomo, ejercido de forma despótica por titulares investidos de cierta noblesse de robe, alimentaría una fortísima reacción social en su contra ${ }^{4}$ y el reproche de la falta de legitimidad. Tanto es así que, en vísperas de la revolución, la Asamblea Nacional suprimiría las justicias señoriales y la venalidad de los oficios judiciales, dando "vacaciones" sine die a los Parlamentos.

La necesidad de una reforma de la justicia, de la criminal en particular, tenía fuerte arraigo en la opinión general de la Francia prerrevolucionaria. Por eso, a la Declaración de Derechos del Hombre y del Ciudadano, de 26 de agosto de 1789, seguiría, en 1790, la reforma de la organización judicial.

La Constitución de 1791 contiene el cuadro general de la nueva justicia francesa, y en ella se hablará por primera vez de la administración de justicia como "poder judicial", (con lo que tiene de sugestivo un cierto estatus de independencia) aunque, ciertamente, el tratamiento de evidente superioridad dado al legislativo y la consideración del juez como mero aplicador (mecánico) de la ley, limitaba de manera sensible el alcance de esa proclama. Mas lo cierto es que se darían pasos de indudable importancia en la consolidación de la instancia judicial como tal. Así, los jueces (de designación electiva y temporal) no podrían ser destituidos sino por causa legal, ni sufrir interferencias en el desarrollo de su función. También se consagró el principio del juez natural. Y se instituyó un Tribunal de Casación, ubicado en el área del legislativo; defiriendo a este la solución de las cuestiones interpretativas, por la vía del référe legislatif.

La napoleónica Constitución del año VIII (1799) introdujo una profunda reforma de la justicia. Según Royer (1995: 425) "con dos artículos assez discrets (...) fijó el cuadro de un estatuto de la magistratura que en sus grandes líneas ha llegado hasta nosotros". Uno, el 41, atribuía el nombramiento de todos los jueces (que no fueran los de paz, de designación electiva) al Primer Cónsul; el otro, el 68, los hacía inamovibles y vitalicios. Además, ante cada jurisdicción, se situaría, en representación del Ministerio Público, a un comisario del gobierno, asistido por uno o varios sustitutos ${ }^{5}$.

El Senatus consulte organique de la Constitution, de 4 de agosto de 1802, completa este esquema, con la figura del Grand-juge ministre de la Justice, al que se encomienda

4 De la que hay precisa constancia en los cahiers de doléances con las quejas dirigidas a los Estados Generales por las asambleas de cada circunscripción francesa encargada de elegir a los diputados. Se dio la circunstancia de que las expresivas del profundo descontento popular con la administración de justicia ocuparon la mayor parte de aquellos. Al respecto, véase Saita (1975: 97 y ss.), donde se recoge, de forma sistemática, un cuadro-resumen al respecto, debido a Clermont-Tonnerre.

5 En el posterior tratamiento legislativo, debido al ordenamiento judicial de 1810, el vértice del instituto será ocupado por el procurador general que, bajo la dependencia del ministro de Justicia, monopolizará la titularidad de la acción penal, ejercida por sus sustitutos, funcionarios del ejecutivo, como delegados. Es una opción organizativa que permanece esencialmente en sus constantes, y no solo en Francia. 
la presidencia del Tribunal de Casación y de los de Apelación, "cuando el gobierno lo juzgue conveniente". También el derecho de surveiller y reprendre a los integrantes de los tribunales y de la justicia de paz. Por otra parte, el Tribunal de Casación, bajo la presidencia de aquel, pasaría a asumir el control y la disciplina sobre los tribunales de apelación y los de lo criminal ${ }^{6}$; mientras que a los tribunales de apelación correspondería idéntico cometido sobre los tribunales civiles y los componentes de la justicia de paz.

Por la Ley de 20 de abril de 1810, a partir de la ya consagrada designación política de los jueces, se establecerá entre ellos un orden jerárquico, similar al vigente en la organización militar. Así se articulará definitivamente a la judicatura como un cuerpo burocrático-piramidal, mediante el traslado de la lógica de la jerarquía de instancias, propia del régimen procesal de los recursos, a la regulación de las relaciones entre sus integrantes, organizándolos como carrera o cursus honorum, superponiendo de este modo a cada momento jurisdiccional otro de carácter jerárquico-administrativo, en definitiva, político. Esto como resultado de una capilar vigilancia del juez, en última instancia, por parte del ejecutivo: en el momento del acceso a la función, merced al sistema de reclutamiento, y durante su ejercicio, por el control intrajurisdiccional, la inspección del modo de actuar (que no se detenía en los límites de la vida privada), la administración de las promociones y a través de la responsabilidad disciplinaria.

Este modelo, conocido como napoleónico, hizo fortuna en la generalidad de los países de la Europa continental y en los de su ámbito de influencia, que asumirían el régimen jerarquizado de carrera propio de la administración pública, para el encuadramiento de sus jueces. Un sistema que ha llegado hasta nosotros y del que hay inequívocas reminiscencias en el modo de articulación interna de los sistemas judiciales de ese ámbito.

\section{LA ELABORACIÓN} TEÓRICA

Dentro de la reflexión teórica producida en torno al juez y a la función jurisdiccional, haré breve referencia a tres momentos por razón de su relevancia, no solo para la adecuada comprensión de la naturaleza de uno y otra, sino también por su influencia en lo relativo al posterior tratamiento constitucional del asunto, en particular, en lo que ha llegado hasta nosotros. Uno es el representado por la aportación de Montesquieu, relativa a la arquitectura más general del modelo (no por casualidad, de matriz francesa). Otro el que se expresa en las aportaciones de Hamilton, Madison y Jay en $E l$ Federalista, relevantes por lo que tienen de profundización y ampliación del relieve de

6 De este modo, el Tribunal de Casación, nacido como órgano de naturaleza más bien administrativa, encargado de evitar las posibles injerencias del judicial en el legislativo, pasaría a ocupar el vértice de la organización judicial en un doble plano, el propiamente jurisdiccional (únicamente conocedor de cuestiones de derecho) y el jerárquico-administrativo. 
la instancia judicial. Y, el último, el relativo a la preocupación de los juristas ilustrados en subrayar, diríamos hoy, la naturaleza esencialmente cognoscitiva del quehacer jurisdiccional y la relevancia en él del papel de las garantías procesales. Las tres son aproximaciones en las que juega un papel esencial, directo o indirecto, el principio de independencia.

La ofrecida por Montesquieu es una perspectiva ciertamente singular, que continúa ofreciendo indudable interés. Y es que, partiendo de una más que razonable consideración pesimista de la experiencia del poder, por su natural propensión al abuso ${ }^{7}$ en sus relaciones con el individuo, adopta un punto de vista, diríamos hoy, rigurosamente jurídico-constitucional, cuyo punto de arranque es la vigencia incondicionada del principio de legalidad.

Aristócrata del Antiguo Régimen, sin duda consciente de la situación de crisis que le afecta a este y, en consecuencia, a su estamento de pertenencia, la vive con una preocupación comprensible que, sin embargo, no le impedirá mirar lejos, tanto que, es claro, el fundamental planteamiento que le debemos desborda con mucho su propio horizonte ${ }^{8}$. En efecto, pues elaboró un modelo centrado en la idea de límite, pensado para garantizar la libertad del ciudadano, diseñando para ello un marco orgánico de separación de poderes ${ }^{9}$ y de subordinación del ejecutivo al legislativo, para lograr que "el poder frene al poder" (1972: 150), y en el que el judicial recibe el encargo de hacer de contrapeso (independiente) del legislador ${ }^{10}$. Como poder también, pero "invisible y nulo" (1972: 152), en cuanto instancia que, participando de la soberanía, es función de la ley, a cuya estricta aplicación se debe, de modo que las sentencias tienen que "corresponder siempre al texto expreso de (esta)" (1972: 153). Por tanto, poder separado, políticamente neutro y equilibrador, rasgos ideales que hoy gozan de plena validez.

A tenor de estas consideraciones, se entiende que toda la reflexión posterior sobre el poder y especialmente el judicial tenga siempre algo de diálogo, explícito o implícito, con Montesquieu. Particularmente fecundo es el mantenido con él por los autores de El Federalista. Sobre todo porque, para estos, el poder cuyo ejercicio despótico habría que prevenir será muy otro que el presente en el imaginario del primero. En efecto, pues aquí se tratará del absolutismo parlamentario, ciertamente impensable para un ilustrado y no se diga para un revolucionario europeo. Una hipótesis abonada por el re-

7 "Es una experiencia eterna que todo hombre que tiene poder siente la necesidad de abusar de él, yendo hasta donde encuentra límites. ¡Quién lo diría! La misma virtud necesita límites" (1972: 150).

8 Es por lo que no puede compartirse el punto de vista de autores como Althusser (1968: 25) y, en cierta medida, Lefebure (1977: 142) que no advierten lo que en el pensamiento de nuestro autor hay de decididamente innovador. Su modelo se mueve en el horizonte de la sociedad estamental; pero, no obstante, hay que decir que opera con categorías, como el principio de legalidad, la separación de poderes y la certeza del derecho que, y menos aún en su articulación, no formaban parte del pensamiento jurídico-político de la época.

9 "Todo estaría perdido si el mismo hombre, el mismo cuerpo de personas principales, de los nobles o del pueblo, ejerciera los tres poderes: el de hacer las leyes, el de ejecutar las resoluciones públicas y el de juzgar los delitos o las diferencias entre particulares” (1972: 151-152).

10 “Tampoco hay libertad si el poder judicial no está separado del legislativo ni del ejecutivo” (1972: 151). 
cuerdo próximo de la cámara de Westminster, visto con el distanciamiento propiciado por su condición de órgano de la potencia colonial, de la que unos Estados Unidos en proceso constituyente se habían recientemente liberado.

De este modo, el punto de partida de la reflexión politológica será el peligro representado por el "despotismo electivo", debido a la concentración del poder en manos de un legislativo eventualmente absoluto (Madison, 1957: 210-211). Tal riesgo llevará a apostar por "una Constitución limitada" (Hamilton, 1957: 331), en virtud de la cautela consistente en que los poderes se encuentren "divididos y equilibrados de tal modo entre distintos cuerpos de magistrados, que ninguno [pueda traspasar] sus límites legales sin ser contenido y reprimido eficazmente por los otros" (Madison, 1957: 212); y de la previsión de "ciertas prohibiciones expresas aplicables a la autoridad legislativa" (Hamilton, 1957: 331), cuyas leyes debe[rán] "ceder" ante la Constitución, en su calidad de "ley fundamental" (Hamiltón, 1957: 344 y 332).

En el contexto del ordenamiento así diseñado, es esencial la plena independencia de los tribunales, a los que, en su condición de "baluartes" de la Constitución, incumbe no solo la protección de los derechos individuales, sino asimismo el deber de declarar nulos todos los actos, incluidos los del legislativo, que de manera evidente la contradigan. Esto -se advertirá- no implica ninguna posición de superioridad política de aquellos, sino que es el efecto genuino de la propia función consistente en interpretar y aplicar la ley y de la misma jerarquía normativa, cuando, como sucede, "la Constitución es de hecho una ley fundamental y así debe ser considerada" (Hamilton, 1957: 330-333).

La aportación de El Federalista a la cultura de la jurisdicción tuvo una triple proyección: potenció la significación positiva de la separación de poderes; contribuyó a reforzar el papel de la Constitución como texto fundamental supraordenado a la ley ordinaria; y revalorizó el rol del juez independiente, como encargado de contribuir, eventualmente, en concreto, al mantenimiento del poder legislativo dentro de los límites de su cometido constitucional, y garante de los derechos de los ciudadanos.

La aludida relevante aportación del pensamiento ilustrado tiene su mejor expresión en Beccaria que, preocupado por el patente desequilibrio en la posición del juez en el proceso penal, con la consiguiente pérdida de imparcialidad, inducida por el sistema inquisitivo a la sazón vigente, denunció con justificada crudeza cómo este le hacía a aquel "enemigo del reo", al estar dirigida su actuación a "extraer de él como de un fundo de su pertenencia todo el provecho posible". Postulando como alternativa a semejante "proceso ofensivo" otro de carácter "informativo", porque su conductor actuase en él como "un investigador indiferente de la verdad" (2011: 175 y 177). Sumamente expresiva en la materia es también la propuesta de Muratori, de un juez que "se quede perplejo (...) para conocer” (1794: 17); y que dedicará un capítulo de su obra a defender la necesidad de "la indiferencia" como actitud de método "necesaria en los jueces" (1794: 119). Digna de mención al respecto es asimismo la posición de Murena, para quien "la 
palabra juez lleva consigo la idea (...) de la verdad", porque "la justicia depende de la verdad de los hechos" (1785: 56 y 66).

En las opiniones que acaban de reflejarse es claramente advertible la preocupación por reconocer en la función jurisdiccional una dimensión epistémica, propia de la actividad cognoscitiva que sin duda le corresponde, puesto que la cabal aplicación de la ley (aproblemática en el contexto de cultura) deberá ir precedida, como necesario presupuesto, de una correcta fijación de los elementos fácticos del caso. Una conciencia presente asimismo en la caracterización de aquella como dotada "únicamente de discernimiento" (Hamilton, 1957: 331).

También en este caso concurrirá la particularidad de que una construcción teórico-política movida por circunstancias propias de la inmediata coyuntura, desbordará amplísimamente este marco, proyectándose en un futuro que es hoy nuestro presente constitucional en la materia.

IV. CARRERA JUDICIAL: EL PROBLEMÁTICO MODELO A LA VISTA DE LOS HECHOS
La cabal percepción de los rasgos caracterizadores del modelo de organización del aparato judicial heredado aconseja orientar la aproximación al asunto en una triple perspectiva, considerando el procedimiento de acceso, la modalidad del encuadramiento orgánico de los profesionales y el estatus de estos resultante.

El sistema de selección ha conocido, básicamente, dos modalidades: el nombramiento discrecional, directamente político, y el de concurso o examen (en ningún caso inocente desde este punto de vista), seguido o no de un periodo de formación. En cualquiera de los procedimientos opera, como presupuesto previo, el dato de la extracción social o de clase, por la exigencia de una cualificación técnica de la que, por lo general, solo disponen quienes disfrutan un cierto nivel de rentas. Requerimiento acentuado en el segundo (el español clásico), que exigirá la capacidad económica necesaria para hacer frente a la preparación de un programa en régimen de exclusividad durante varios años. Por eso resulta tan pertinente el dictamen de Casamayor (1957: 143): "La magistratura no se ha vendido a una clase social, la clase burguesa. Esta la ha adquirido". Sobre este presupuesto incidirá luego, reforzándolo, el fenómeno ampliamente constatado de la dinámica en buena medida endogámica inscrita en la reproducción de los cuerpos de funcionarios judiciales y del ministerio público.

En el caso de nuestro país, como se sabe, el ingreso en la judicatura requiere la superación de algunas pruebas de suma dureza, de índole puramente memorística, consistentes en la asimilación mecánica de los textos legales y también de algunas nociones esquematizadas, esterilizadas en clave de "contestaciones", para ser recitados en 
un tiempo récord ante la comisión examinadora. De donde resulta que lo estimulado y lo puesto a prueba por este peculiar régimen de selección no es, precisamente, la calidad intelectual y ni siquiera la formación jurídica del examinando, si no su capacidad de asimilación y el hábito de aceptación acrítica de lo que pudiera llegarle por una vía de autoridad.

Superadas las pruebas selectivas, los ya jueces serían integrados en un cursus honorum de disposición vertical, enmarcado en el área del ejecutivo a través del Ministerio de Justicia, a cuyo titular correspondían importantes atribuciones en materia de promociones. En concreto, el discrecional nombramiento de los integrantes del Tribunal Supremo, que, por su parte, junto al superior cometido estrictamente jurisdiccional, acumulaba el de gobierno, también del máximo rango en el orden funcionarial, de los demás integrantes de la carrera. Es decir, el régimen de atribución de destinos, ascensos y el disciplinario.

No hace falta decir que el tipo de articulación jerárquica imprimirá en los así escalafonados un permanente y fuerte estímulo a la progresión en aquella, un avance que dependerá del grado de adecuación de sus actitudes y actuaciones a los criterios y las expectativas del vértice corporativo, con lo que ello implica de fuerte inducción al conformismo en la adopción de las decisiones, y de dependencia, por tanto. Con inevitable proyección, pues, en la práctica jurisdiccional a través del régimen de instancias, debido a que la relación existente entre los jueces ubicados en cada una de estas, no será meramente procesal sino también político-administrativa, de supra y subordinación. Lo que quiere decir que cada tribunal ad quem, además de competente para conocer en cada caso de la sentencia impugnada, contará, regularmente, con alguna clase de atribuciones de directa o indirecta incidencia en el futuro profesional del juzgador de la inferior instancia. En semejante marco organizativo, además, el instrumento disciplinario propiamente dicho -por lo general, complementado por otro, regular y capilar, de inspección- reviste especial relevancia, cual dispositivo de cierre; que ha operado prácticamente como mecanismo de control ideológico, a partir de la descripción de las conductas sancionables en términos de enorme amplitud y ninguna taxatividad. Baste recordar al respecto la previsión del artículo 734.5 de la Ley Orgánica del Poder Judicial de 1870 (vigente hasta 1985), que preveía sanciones de esa índole para los jueces que, "por las irregularidades de su conducta moral o por vicios que les hicieren desmerecer en el concepto público, comprometieren el decoro de su ministerio".

El estatus de estos peculiares empleados públicos de la jurisdicción es el internamente contradictorio de funcionarios (supuestamente) independientes que se ha señalado. En cuanto sedicentemente servidores profesionales de un principio, el de independencia, sin embargo, objetivamente negado de manera esencial en los entresijos del complejo organizativo. Lo que, como no podría ser de otro modo, contará con inmediata expresión en los valores profesados, que tendrían a aquel como eje, pero en versión netamente ideológica, es decir, como una forma de falsa conciencia acerca del 
propio rol y de su función social. En efecto, pues el sistema, que lo celebra con artificiosa y retórica grandilocuencia en las diversas manifestaciones de su folclore, excluye de sus articulaciones los presupuestos organizativos imprescindibles para dotarlo de efectividad. La consecuencia es que del ethos profesional de aquellos forma parte una tendencial subalternidad a los centros de poder y la inclinación al autoritarismo en el ejercicio de la función. Con particular traducción en el carácter monologante de las actitudes, en un sentido autocrático de la libre convicción, abierto al uso de una incontrolada discrecionalidad máxima, y en un entendimiento silogístico (mecánico) del modo de decidir, con natural prolongación en el decisionismo inmotivado presente en las resoluciones ${ }^{11} \mathrm{y}$ también el uso en extremo generoso de la prisión preventiva.

El juez-resultado, fruto del señalado conjunto de factores, es el propio del estado liberal o legislativo de derecho, en realidad, juez del poder, según ha demostrado una demoledora experiencia histórica, de historia relativamente próxima. Me refiero a lo sucedido con los espantosos nazifascismos europeos y las atroces dictaduras del Cono Sur de América Latina ${ }^{12}$. En efecto, pues los jueces -cultores, no importa insistir, del valor independencia (en la versión aludida)- se integraron masivamente, con docilidad y la máxima funcionalidad, cual si afectados por alguna predisposición genética, en políticas, no simplemente antidemocráticas, sino directamente criminales. Y expresaron evidentes dificultades para aceptar y adaptar sus prácticas a las nuevas constituciones rígidas con sus tablas de derechos, en los momentos de restablecimiento de la democracia.

\section{HACIA UN CAMBIO DE MODELO}

Una de las ricas particularidades de la interesantísima experiencia constituyente que alumbró la Constitución italiana de 1948, es que tiene algo de ajuste de cuentas con el antimodelo que acaba de examinarse. El resultado, diría, fue la adveración,

\footnotetext{
11 El modo autocrático de decidir que connota de una forma esencial la manera de operar del juez del modelo, tiene su punto de arranque en una inteligencia del principio de libre convicción informada por un sentido profundamente irracional, casi mágico, de la inmediación. Esta, supuestamente, le conferiría una insólita capacidad de apreciación del verdadero sentido de lo transmitido verbalmente en sus declaraciones (prueba directa) por imputados y testigos, mediante la lectura de su gestualidad. Semejante modo de aproximación a la quaestio facti produciría en el jurisdicente una suerte de estado psicológico de certeza, de imposible traducción en palabras, en cuanto perteneciente al reino de lo inefable y, como tal, no susceptible de motivación. El círculo se cerraría con una no menos falsa conciencia de la aplicación casi mecánica del derecho en la aludida clave silogística que daría como resultado la decisión. Ciertamente inmotivada y por ello incontrolable, desde luego, en lo relativo al tratamiento del material probatorio.

12 En el caso de Alemania, los jueces y fiscales después de haber sido el verdadero partido de oposición a la República de Weimar, se integraron masivamente en la Federación de Juristas Nacionalsocialistas (Müller, 2009: 278 y ss.). En el caso de Italia, de alrededor de 4000 magistrados, solo 17 fueron separados de sus puestos por el régimen mussoliniano (Guarnieri, 1997: 252). En España, Lanero Táboas (1996: 236) ha fijado en 149 el número de depurados administrativamente (de las tres carreras, judicial, fiscal y secretariado), entre los años 1936-1944. En la materia puede verse también con provecho: Fernández-Crehuet (2011) y Portilla Contreras (2019). En fin, por su carácter asimismo emblemático, acerca de la relación del poder judicial chileno con la dictadura de Pinochet, cfr. Matus Acuña (2000) e Hilbink (2014).
} 
asunción y desarrollo normativo de la lúcida y comprometida previsión del artículo 16 de la Declaración de 1789: "Toda sociedad en la cual la garantía de los derechos no está asegurada ni la separación de poderes establecida no tiene Constitución”. En efecto, pues el nuevo texto consagró jurídicamente como fundamentales, con el máximo rango normativo, los históricos derechos humanos, incluidos ahora los sociales. Predisponiendo, para procurar su efectividad, la instancia jurisdiccional de garantía representada por una magistratura independiente, de independencia reforzada, en cuanto extraída del ámbito del ejecutivo, y por un juez dotado de efectiva independencia funcional en su propio ámbito. Tal es la consecuencia de atribuir la gestión del estatuto judicial a un nuevo órgano, el Consejo Superior de la Magistratura ${ }^{13}$, que, además de producir ese primer efecto, referido a la institución como tal, según enseguida se verá, llevaba también consigo el no menos relevante de eliminar, tanto la dependencia de la magistratura del poder ejecutivo, como las posiciones de poder (y dependencias, por tanto) de unos jueces sobre otros, asegurando la existencia entre estos de un solo tipo de relación, la estrictamente jurisdiccional. Todo con el objeto de hacer real su exclusiva sumisión a la ley, promoviendo al mismo tiempo la necesaria tendencial unidad en la lectura de esta, a través del régimen de instancias y recursos y no por medios jerárquico-administrativos, al fin políticos. Ahora, además, con la inédita obligación de cuestionar aquella, antes de aplicarla, ante la Corte Constitucional, en el caso de hallarla aquejada de algún desajuste de orden sustancial con el texto fundamental.

Este último, en su artículo 107.3, disponía: "los magistrados se distinguen entre sí solamente por la diversidad de funciones". Un precepto de alcance ciertamente revolucionario, que, en sí mismo y con su desarrollo legislativo, fue a representar el más profundo cuestionamiento del régimen de carrera judicial, auténtica columna vertebral del modelo napoleónico. En efecto, pues tal nueva disposición, al impedir cualquier diferenciación entre jurisdicentes por razón la jerarquía de orden escalafonal, consagraba su igual dignidad en todas las instancias procesales: lo propio de una función sin otro cometido que el de "decir el derecho" en condiciones de independencia e imparcialidad. El efecto fue la "abolición de la carrera" propiamente dicha, a través de una serie de medidas legales, adoptadas a partir de 1951 y a lo largo de treinta años. Es como se produjo el tránsito de la férrea jerarquización de los magistrados en los ocho grados de la carrera a su distribución en tres funciones (de tribunal, de apelación y de casación), con la consagración del llamado principio de escalafones abiertos (ruoli aperti). Así, el mecanismo de promoción dejaba de ser resultado de una forma de competición entre

13 De composición mixta: 2/3 de jueces elegidos mediante sufragio por y dentro de la propia magistratura y 1/3 de juristas de extracción parlamentaria. El Consejo, expresión de lo que Pizzorusso (1984: 293) llama "pluralismo institucional" es "un órgano compuesto conforme a criterios que, combinados entre sí, emplean el factor electivo y el de la cualificación profesional, la designación de los operadores del sector y la de los elegidos por el pueblo". 
candidatos al ascenso para, en virtud de un sistema de selección negativa, convertirse en algo automático ${ }^{14}$.

Los detractores de esta opción, preferentemente situados en los puestos superiores del viejo escalafón, le han reprochado la eliminación no solo del mecanismo del ascenso, sino, a la vez, del (supuesto) estímulo hacia la autoformación permanente y la mejora profesional. Pero, dicho con palabras de Calamandrei (1960: 98 y 1001), lo realmente eliminado fueron "los peligros de la carrera" y el "conformismo de casta, concordante con el criterio de los superiores”. Justamente denunciados también por Battaglia (1962: 28) para quien "no hay medio más eficaz para [la] corrupción [de los jueces] que el consistente en disponer de sus promociones”. De ahí la importancia, subrayada por Varaut (2004: 20), de poner al profesional de la jurisdicción a salvo, incluso "de las debilidades de la ambición legítima"15.

De otra parte, a esa manida objeción cabe, a su vez, objetar que el mismo régimen de instancias y recursos, que comporta el más que probable reexamen crítico por otro tribunal de cada resolución de fondo emitida, induce ya ciertamente un estímulo hacia la mejora de la calidad del propio trabajo. Que, de otro lado, puede/debe reforzarse con adecuadas políticas de estímulo de esa misma orientación, fundadas en limpios criterios de profesionalidad, susceptibles, a su vez, de ser reforzadas en sus efectos mediante una no menos limpia y transparente política de nombramientos.

VI.

CONSTITUCIONALISMO DE DERECHOS Y MODELO DE JUEZ
La durísima experiencia de los nazifascismos puso de manifiesto lo que ya antes había dado motivos para ser una evidencia: que la democracia representativa, librada a su propia dinámica exclusivamente política, puede envilecerse e incluso enloquecer. Por eso, sin perjuicio de reconocerle un incancelable y legítimo ámbito propio, la necesidad de circundarla de límites de jurídicos, en prevención de eventuales degradaciones. De ahí el paso a un constitucionalismo rígido fuertemente asentado en derechos, ahora fundamentales, dotados de efectiva normatividad. Una opción cuya razón de ser

14 En efecto, pues, alcanzada la antigüedad necesaria y contando con el juicio de idoneidad emitido por el Consejo Superior de la Magistratura, se obtenía la aptitud para entrar en el desempeño de otra función, con los efectos económicos correspondientes, si bien con derecho a permanecer en la prestación de la que se estuviera ejerciendo. En el caso de no ser declarado idóneo, el magistrado tendría que someterse a nueva valoración una vez transcurridos dos años. De este modo, la función se disociaba del puesto escalafonal. Solo para el acceso efectivo a la Corte de Casación y a puestos directivos, por la especificidad de su cometido y debido también al número cerrado de plazas, seguiría rigiendo el régimen de concurso de méritos entre los magistrados aptos en principio para su acceso a una y otros. 
tampoco podría resultar más obvia, según hace ver Häberle (1993: 51), para quien aquellos son el auténtico "fundamento funcional" de la democracia, a través de cuyo ejercicio "se realiza un proceso de libertad que constituye un elemento esencial de esta". En efecto, pues ¿cómo pensar una democracia sin ciudadanos con derechos fundamentales suficientemente garantizados? De otro modo: ¿política y democracia para quién?

Es así como, en el estado constitucional, la kelseniana pirámide normativa se enriquece con un nuevo escalón, precisamente en la cúspide, pues tal es a lo que equivale el injerto en el ordenamiento de lo que Ferrajoli (2011: 872-874) ha descrito eficazmente como una "dimensión sustancial" no solo del derecho sino también de la democracia.

Esta forma de constitucionalización de los derechos y su nuevo papel en el contexto del orden jurídico resultante, reclama la existencia de una institución de garantía independiente que, asimismo por imperativo constitucional, es la representada por la jurisdicción. Una instancia cuyos rasgos caracterizadores dependen directamente de la naturaleza de la función y de su papel institucional. Esta, según se ha anticipado, se concreta en la comprobación de la existencia de eventuales actos inválidos o ilícitos (de cualquier procedencia, incluida la oficial), para disponer en tal caso su anulación o su condena, con la atribución a sus responsables de las consecuencias que en derecho pudieran corresponder.

La jurisdiccional es así una actividad, ciertamente de poder, pero de naturaleza esencialmente cognoscitiva, cuyo cometido se cifra en la identificación de supuestos de hecho legalmente previstos y en su caracterización jurídica, para determinar las eventuales consecuencias de este carácter asociadas a su ejecución. Es por lo que está dotada de la ya aludida consistente dimensión epistémica, puesto que si se enjuicia es para conocer, para obtener un conocimiento de calidad. Lo que demanda, tanto la colocación del sujeto jurisdicente en una posición idónea a tal efecto, como la asunción de ciertas pautas y cautelas en el modus operandi. A asegurar lo primero se orientan las garantías conocidas como orgánicas, predispuestas para dotarle de un estatuto de independencia, necesario para evitar que su colocación en el contexto estatal pudiera investirle de una cierta condición (implicación) de parte política; a lo segundo las garantías procesales, que buscan asegurar su imparcialidad, evitando que el juez, en el ejercicio de la jurisdicción, pueda moverse por cualquier interés preconstituido que no sea el de la comprobación, tendencialmente objetiva, de lo efectivamente sucedido en el caso concreto, para decidir sobre él exclusivamente en derecho. La relación de necesidad que conecta a estos dos valores convierte al primero en una suerte de metagarantía, imprescindible para posibilitar el juego de las demás.

De aquí se sigue, como efecto, que la función jurisdiccional siendo, como se ha dicho, función de poder, no sea sin embargo política, por más que sus resoluciones, que podrían afectar, como afectan en muchos casos, a actos y decisiones de sujetos públicos, lleguen a producir, como con frecuencia sucede, graves efectos de ese carácter. Tampoco se trata de una instancia representativa ni de participación, que, no obstante, 
es (indirectamente) democrática, por su exclusiva vinculación a la ley, fruto genuino de instituciones que son las que, por antonomasia, participan de ese doble carácter; y porque su cometido consiste en procurar la igual garantía de los derechos de todos frente a todos. Esto la dota de un carácter eventualmente contramayoritario, en cuanto solo sujeta a la voluntad expresada en la ley (que es ley más constitución), que muy bien podría no ser la actual de la coyuntural mayoría política investida del poder en acto.

Así resulta que lo que en ocasiones ha sido (des)valorado como déficit de legitimidad de la jurisdicción, expresa, precisamente la astucia de la razón jurídico-política que funda su deber ser constitucional. Su peculiar condición de poder, que es el de "decir el derecho", que únicamente cobra cuerpo en el juez competente para el tratamiento y la decisión del caso concreto. Por eso la peculiar colocación de este en el estado-aparato, en la que Zagrebelsky (1982: 784) ha calificado de "posición mediana entre estado y sociedad".

VII. INDEPENDENCIA: REQUERIMIENTOS EN MATERIA DE ESTATUTO JUDICIAL
Dando por supuesta la garantía de una independencia externa, de la magistratura como institución, por su desconexión del poder ejecutivo en los términos ya ilustrados, en el momento de dotar a la concreta independencia del juzgador del imprescindible soporte institucional, los interrogantes suelen girar en torno al quién y al cómo de un régimen organizativo que, tradicional y pacíficamente, ha sido caracterizado como el propio de una acción de "gobierno". Tanto es así que esta idea sigue (impropiamente) presente en el artículo 122.2 de la Constitución española, donde se trata al Consejo General del Poder Judicial de "órgano de gobierno".

Pues bien, así las cosas, la pregunta obligada es acerca de la compatibilidad de este criterio con la función constitucional consistente en impartir, de forma independiente, justicia. Y esto obliga también a introducir un tercer, que, quizá, debería ser primer interrogante: ¿gobierno?

El poder que se expresa en el ejercicio de la función jurisdiccional constitucionalmente entendido, tiene un carácter difuso, en el sentido de que todos los jurisdicentes, cada uno dentro de su ámbito de competencia, están investidos de plenitud de jurisdicción, y en el desempeño de cuyo cometido gozan, por tanto, de idéntica y la misma dignidad, sea cual fuere el lugar ocupado por cada uno de ellos en el organigrama institucional y el momento procesal en el que se produzca el desarrollo de aquel. A partir de tal presupuesto, cada uno de estos actores experimenta una doble, exclusiva sujeción: a la ley y a un imperativo de racionalidad cognoscitiva. Así, gestionar la administración de justicia es organizar y asegurar, sí, pero única y exclusivamente esta doble, peculiar 
sujeción. Por eso la impropiedad de denotar a tal actividad como de gobierno. En efecto, pues "gobernar" implica ejercicio de poder con dirección política y determina en el gobernado el sometimiento a un status subiectionis, a una relación general de sujeción. Es una clase de actividad que se concreta en actuaciones con un fuerte componente de selección y definición de objetivos y asignación de recursos en un marco de notable discrecionalidad, cuyos operadores forman parte de un cuerpo jerarquizado de funcionarios, en el que cada inferior actúa por delegación y bajo la dirección de un superior.

A tenor de esta consideración, debe afirmarse que en la jurisdicción del estado constitucional no hay nada que gobernar en el sentido político-administrativo del término; pues lo requerido por la gestión del estatuto del juez es la adopción de decisiones singulares, en un marco reglado y en el ejercicio de una moderada discrecionalidad, cuyo uso debe justificarse de manera expresa y será, además, impugnable. Es por lo que Pizzorusso (1990: 97) optó por referirse al conjunto de actuaciones en las que tal actividad se concreta como "administración de la jurisdicción". Que demanda la existencia de un órgano de vértice, autónomo, no de gobierno y tampoco de poder en sentido político, sino de garantía, esencialmente deliberativo, que, por eso, reclama en su interior, más que mayorías fuertes, pluralismo efectivo, por la presencia en él de un amplio abanico de posiciones de valor, que, llegado el caso, le dote de una imprescindible capacidad de conflicto, cuando se trate de dar apoyo a actuaciones y decisiones judiciales legalmente fundadas pero políticamente incómodas.

Este cambio en la cúspide habrá de tener prolongación en un modo de articulación de los profesionales esencialmente horizontal, en el que, en general, los ascensos pasen a ser traslados; que cuando sea a puestos que demanden una especial cualificación se produzcan en virtud concursos dotados de la transparencia imprescindible. La concentración de las antiguas funciones gubernativas en el Consejo -allí donde este existe en los términos del sistema italiano- ha comportado la transformación esencial en el carácter de las presidencias, por la inexistencia de algo que presidir en sentido políticoadministrativo del término y que, por esto, deberían ser electivas o rotatorias. También puede hablarse de un cambio en el propio significado de la casación, ahora "suprema" solo por última ${ }^{16}$, que demanda un régimen de acceso exclusivamente determinado por los constitucionales principios de "mérito y capacidad" (artículo 103.3 de la Constitución), aquí con tantísima frecuencia inobservados. Asimismo, en fin, debería producirse un replanteamiento del sistema retributivo en sentido tendencialmente igualitario, disociado de cualquier idea de rango, y en el que no habría razón de ser para otras diferencias de trato que las determinadas por la antigüedad y la especial dificultad del encargo.

16 La Ley Orgánica 5/1997, cediendo a la presión de los magistrados del Tribunal Supremo, constituidos a estos efectos en verdadero lobby, les atribuyó un anómalo "estatuto especial", dirigido, en última instancia, a justificar un aumento de las retribuciones. Anómalo, porque el artículo 122, 1 de la Constitución dice que "los jueces y magistrados (...) formarán un cuerpo único". Además, el precepto, inmediatamente antes, se refiere al estatuto de estos como único. Y "estatuto", según el Diccionario de la RAE es: la "regla que tiene fuerza de ley para el gobierno de un cuerpo". 
Pues bien, llegados a este punto, se abre la pregunta relativa a qué es lo que se trataría de administrar, que tiene una respuesta sencilla en su formulación: las vicisitudes profesionales relativas al ejercicio independiente de la jurisdicción. Las fisiológicas y las, por así decir, patológicas que eventualmente pudieran producirse, a las que se hará aquí una sucinta referencia.

Dentro de las primeras tiene particular importancia la modalidad del acceso que, a su vez, en rigor, abre con carácter previo un doble interrogante relativo al modelo de juez y a la cultura de la jurisdicción que se trataría de promover. Pues, no hay duda, el diseño y el uso de cualquier proceso de selección tendrá como presupuesto, aunque sea implícito, la respuesta a ambas cuestiones. Por lo que se ha anticipado, no haría falta decir que este es un asunto muy mal resuelto en España, que representa un grave problema real permanentemente eludido, que no puede ser afrontado en estas páginas. Pero sí cabe afirmar que cualquier sistema al respecto habría de estar, primero, orientado a seleccionar a los futuros profesionales por un procedimiento racional de examen, con un criterio obviamente igualitario, idóneo para la detección en ellos de la clase de valores y facultades intelectuales, y no solo los demandados por el correcto ejercicio de la función. Un primer paso con imprescindible continuidad en un periodo de intensa formación durante cierto número de años en un centro ad hoc. Formación, obviamente, técnica de gran rigor, pero también cultural (y subrayo lo de cultural), bajo la dirección de un profesorado competente, multidisciplinar y pluralista desde el punto de vista político-cultural.

Situados ya en el plano del regular ejercicio de la jurisdicción, este demanda la prestación de algunas garantías imprescindibles, a las que aquí solo cabe referirse muy sintéticamente. Unas de carácter formal o de entorno, otras de naturaleza sustancial.

De las primeras, goza de particular relevancia la inamovilidad, a la que puede decirse asociada la preconstitución o predeterminación legal. Aquella debe proyectarse sobre la sede, la función y el puesto concreto en el ejercicio de esta, para impedir cualquier posible alteración que carezca de causa legal, y habrá de ser adoptada por el órgano competente, de acuerdo con un procedimiento regular y contradictorio y mediante decisión motivada susceptible de impugnación. La segunda cuenta como antecedente con el carácter naturalmente no fungible de los jueces por razón de su perfil ideológico, y de ahí la necesidad de administrar las legítimas diversidades resultantes con la máxima neutralidad y objetividad mediante el automatismo en la asignación de las causas y pleitos, según criterios rigurosamente predeterminados ${ }^{17}$. En esta área tiene también encaje el régimen de incompatibilidades que deberá ser, en general, muy riguroso y, en particular, en lo relativo al eventual desempeño de posibles encargos extrajudiciales en situación de compatibilidad.

17 Al respecto, hay que llamar la atención sobre el recurso a un instituto excepcional, la "comisión de servicios", que, en estos años, ha sido objeto de utilizaciones sumamente cuestionables en la Sala de lo Penal de la Audiencia Nacional, relacionada con los procesos del caso Gürtel. En general, sobre el relevante asunto de la predeterminación legal del juez, no del todo bien resuelto entre nosotros, cfr. Andrés 2018. 
Las garantías denotadas como sustanciales miran a asegurar la imparcialidad en el momento de la decisión, mediante previsiones orientadas a evitar eventuales contaminaciones de carácter preferentemente ideológico. A esta finalidad responde la prohibición de la adscripción a partidos políticos y organizaciones afines. Asimismo lo hacen algunas cautelas previstas para el supuesto de posibles incursiones en la política acti$\mathrm{va}^{18}$, para el momento del retorno a la actividad jurisdiccional. Esta es una posibilidad que, a mi juicio, tendría que descartarse legalmente. En efecto, pues el de la política es el terreno de las, en el mejor de los casos, legítimas parcialidades y, lamentablemente, en los hechos, también el de las degradaciones partitocráticas, tan profundamente instaladas en las prácticas de las formaciones políticas, en las que una abrumadora experiencia permite afirmar que reinan hábitos y formas de relación rigurosamente incompatibles con los propios de la actividad jurisdiccional ${ }^{19}$.

Cuestión relevante en materia de estatuto del juez es la relativa a la valoración del desempeño, de pertinencia, en principio, poco cuestionable en esta como en cualquier otra función de carácter público, pero que, por la peculiar naturaleza de la de que aquí se trata, tendrá que estar rodeada de algunas cautelas imprescindibles. En efecto, pues dado que, de una u otra forma, habrá de traducirse en una evaluación de la calidad de las prácticas y de las resoluciones jurisdiccionales, debería atenerse a requerimientos de carácter exclusivamente técnico-profesional, sin entrar en modo alguno en valoraciones de contenido, únicamente permitidas en el marco del régimen de instancias y recursos. Esto para evitar una restauración, por otra vía, de los perniciosos efectos de control ideológico e inducción al conformismo generados por el dispositivo de la vieja carrera, al que, de no adoptarse con rigor las necesarias precauciones, podría venir a sustituir.

En la perspectiva de la garantía de la independencia judicial, es de una relevancia esencial el tratamiento del régimen disciplinario, en sí mismo tan necesario como peligroso. En su versión tradicional, ya se ha dicho, tenía atribuida la función de contribuir a neutralizar represivamente cualquier posible uso impropio de aquella, no conjurado con carácter previo por los impropios mecanismos de fiscalización intrajurisdiccional y los inscritos en la misma articulación en carrera. En rigor constitucional, deberá estar exclusivamente orientado a sancionar graves incumplimientos de deberes profesionales, legalmente previstos con la necesaria taxatividad, por un procedimiento de índole rigurosamente jurisdiccional en cuestión de garantías. En la materia, en la generalidad de los países, existe amplia experiencia, histórica y en ocasiones actual, del uso abusivo de la disciplina para interferir en actuaciones propiamente jurisdiccionales incómodas, por completo inadmisible.

\footnotetext{
18 Una opción que, después de haber recibido un razonable tratamiento restrictivo por Ley de 20 de febrero de 1978, en tiempos de Adolfo Suárez, mediante la Ley Orgánica del Poder Judicial de 1985 y otras posteriores, bajo la denominación de "servicios especiales", ha venido a restaurar la institución franquista de la "excedencia especial".
}

19 A título puramente indicativo, bastará con hacer referencia al modo como la perniciosa influencia de la partitocracia lleva proyectándose, desde hace decenios, en la desoladora experiencia del Consejo General del Poder Judicial (a la que más adelante se hará concreta referencia), con la inevitable grave proyección en una cuestión tan relevante como la política de nombramientos, entre otras. 


\section{LA DESOLADORA \\ EXPERIENCIA \\ ESPAÑOLA ACTUAL}

La Constitución de 1978 hizo objeto de un tratamiento esencialmente nuevo al régimen jurídico de la administración de justicia. De una parte, al romper de forma drástica con el anterior, caracterizado por la colocación de esta y de sus actores bajo la dependencia del ejecutivo; y de otra, y como consecuencia, por el sensible reforzamiento de la independencia, debido al desplazamiento de la totalidad de las competencias relativas a la gestión del estatuto del juez al Consejo General del Poder Judicial. En efecto, pues, a pesar de que el artículo 122 de aquella, en su primer apartado, mantiene una expresa referencia a la "carrera" y aunque en el tercero habla de "categorías", lo cierto es que el texto fundamental puso fin al gobierno ministerial y acabó con las atribuciones de esta índole, antes conferidas en particular a la alta magistratura, pero inscritas en general en todo el organigrama.

El primer desarrollo constitucional, por la Ley Orgánica 1/1980, trató al Consejo de una forma razonable en materia de competencias; pero no en lo referente a la integración de su componente judicial. Ello, debido a la sobrerrepresentación de la jerarquía, y por la fijación del mínimo de un 15\% de los jueces para acceder al asociacionismo y, con esto, a la conformación electiva de aquel (claramente destinado a excluir de este al sector progresista de la judicatura, el procedente de Justicia Democrática); a lo que fue a unirse la previsión de un sistema de sufragio "mayoritario corregido". Todo destinado a entregar, como efectivamente se entregó la institución, en su primer mandato, a la recién nacida Asociación Profesional de la Magistratura, promovida y controlada por la élite judicial del franquismo.

Este modo de actuar, tan políticamente instrumental y tan sectario, suscitó una reacción de similar perfil de la mayoría socialista salida de las urnas de 1982, en franca contradicción, por cierto, con las actitudes, incluso de un judicialismo extremo, mantenidas por ella en la oposición. La postura de esta formación con respecto al Consejo -que tuvo por vehículo la Ley Orgánica del Poder Judicial de 1985²0 - acabó concretándose en la asunción de la conocida como "enmienda Bandrés", que extendió la elección parlamentaria a todos los vocales. Esto, se dijo, con el fin de asegurar la legitimación democrática de la judicatura y de la propia institución; a la que, con llamativa paradoja, una vez democráticamente legitimada (mediante su entrega a la partitocracia), se le privó de una parte muy importante de sus competencias, comprendida, incluso, la gestión de las pruebas de ingreso en la judicatura. También se produjo una significativa anticipación de la edad de jubilación (de los 72 a los 65 años) ${ }^{21}$. Por lo demás, el texto

20 Para un examen con cierto detalle de su proceso de elaboración y de su contenido, cfr. Andrés y Movilla (1986: 75 y ss.) y Andrés (2015: 186 y ss.).

21 De corte similar a la adoptada por la actual mayoría de la ultraderecha de gobierno en Polonia, en relación con los jueces del Tribunal Supremo, que ha sido justamente descalificada por el Tribunal de Luxemburgo, como violadora "[d]el principio de inamovilidad del juez, inherente a su independencia", en su sentencia de 24 de junio de 2019. De índole semejante es la sentencia de la misma instancia de 6 de noviembre de 2012, relativa a Hungría. 
acusaba notables deficiencias, seguramente fruto de la ausencia de un debate riguroso y abierto, de lo inopinado y oportunista del cambio de criterio de la mayoría socialista en aspectos fundamentales de la materia objeto de regulación, y de la precipitación, debida al interés en que el nuevo sistema de elección de los vocales pudiera regir ya la renovación del Consejo, que cumplía su primer mandato en octubre de 1985. Huelga decir que el segundo mandato contó con una consistente mayoría de extracción socialista.

Siguieron distintas reformas, en las que aquí no cabe entrar, hasta llegar a la promovida por una mayoría popular, mediante la Ley Orgánica 4/2013, a la que se debe un drástico redimensionamiento a la baja del Consejo en su carácter de órgano colegiado. Esto, por el incremento de las competencias de la Comisión Permanente, cuyos vocales pasaron a ser los únicos ejercientes a tiempo completo; y por el reforzamiento de las del presidente, el solo estable en su dedicación durante todo el mandato, con notable capacidad práctica de maniobra para configurar la Permanente, determinar su funcionamiento y condicionar sus decisiones. También se incrementó la presencia en el órgano del sector jerárquico de la magistratura. Y, en fin, se produjo un cambio esencial en materia de nombramientos (de magistrados del Tribunal Supremo, de los dos del Tribunal Constitucional que corresponde al CGPJ y, en general, de cargos judiciales), para los que, en lo sucesivo, bastaría la mayoría simple ${ }^{22}$.

Los desarrollos legislativos de 1980, 1985 y 2013, brevemente reseñados, fueron de un perfil, podría decirse, expedicionario, en cuanto orientados, no a dar un tratamiento constitucionalmente respetuoso al CGPJ, sino a operar políticamente en/con él en la coyuntura, con efectos que se han manifestado ciertamente catastróficos, desde luego, en lo relativo a la garantía institucional del principio de independencia.

Si hubiera que caracterizar de la forma más expresiva lo ocurrido a partir de la entrada en vigor del sistema de elección de los vocales introducido en 1985, bastaría decir que los partidos, en especial los mayoritarios, no es que estén representados, es que llevan más de seis lustros efectivamente presentes y activos como tales en el Consejo, convertido así en un escenario más de la política general ${ }^{23}$. La consecuencia es que en tal marco no se hace política de la justicia, sino política tout court con la jurisdicción, que es como decir contra esta entendida en su sentido genuinamente constitucional. Algo a lo que muy lamentablemente han contribuido también, con sus actitudes co-

22 La Ley Orgánica 4/2018, en lo que aquí interesa, ha deuuelto al CGPJ la plena colegialidad, mediante el restablecimiento de la dedicación exclusiva de todos sus integrantes; $y$ ha retornado también a la exigencia de un quorum cualificado de tres quintos para los nombramientos a que acaba de hacerse referencia. La misma ley ha reformado el art. 326 LOPJ en materia de nombramientos discrecionales de cargos judiciales, estableciendo que estos deberán ajustarse a las bases relativas a los méritos requeridos, que tendrían que ser valorados conforme a criterios asimismo preestablecidos, debiendo reflejarse esa evaluación en una propuesta motivada. Es una exigencia de inspiración constitucional tan obvia que no necesitaría siquiera expresión legal, pero que ha sido sistemática y endémicamente desatendida por el Consejo General del Poder Judicial en todos sus mandatos. 
misariales, gran parte si no la mayoría de sus integrantes de procedencia judicial y del ministerio público y las propias asociaciones judiciales, con su colaboración activa o con su indiferencia ${ }^{24}$.

No cabe aquí extenderse en el examen de la nutridísima fenomenología útil para ilustrar lo que acaba de afirmarse. Bastará con apuntar algunos relevantes momentos de esta, tomando en especial consideración ciertos aspectos de la ejecutoria del Consejo en el actual mandato, que, con mayoría popular y una minoría (la llamada progresista) connotada por su irrelevancia, bajo la férrea presidencia de Carlos Lesmes ${ }^{25}$, ha llevado al extremo todo lo negativo del sistema inaugurado por la LOPJ de 1985. Por eso su carácter ciertamente emblemático.

En la raíz de lo acontecido está el dato de que, desde 1985, sin respetar el constitucional quorum de tres quintos en la elección de los componentes del CGPJ, se optó por la pura y simple distribución de los puestos dentro de este, de modo que cada formación política con posibilidades pudiera poner en él a personas de su exclusiva confianza o interés (confianza o interés político-partidistas, claro está). Así, aquellos no han sido nunca designados en las sedes parlamentarias correspondientes sino en las de los partidos mayoritarios ${ }^{26}$. Donde se pactó, también con regularidad, el nombre del presidente, vergonzantemente ratificado, que no elegido, por los veinte integrantes del Consejo, estrenándose así en clientelar obediencia, ya en el primer pleno ${ }^{27}$.

Sobre la calidad de la ética pública que informa esta clase de tratos, vino a arrojar una luz, ciertamente esclarecedora, el indecente whatsapp remitido por Ignacio Cosidó, a la sazón portavoz del Partido Popular en el Senado, a los senadores de esta formación. Refiriéndose al acuerdo alcanzado en ese momento en la negociación con

24 Me refiero en particular a Asociación Profesional de la Magistratura y a Jueces para la Democracia, que, puede decirse, cada una ha contado con su partido de referencia. Si bien concurre una relevante particularidad: que la primera ha mantenido siempre una actitud monolítica, de plena subalternidad al Partido Popular y de aceptación acrítica de sus planeamientos y de tal estado de cosas. En cambio, en la segunda, la participación en el sistema de elección generado por la Ley Orgánica de 1985, en posición privilegiada merced al apoyo socialista, ha sido siempre motivo de aguda polémica, objeto de debate y causa de confrontación interna de dos posiciones netamente diferenciadas y sistemáticamente enfrentadas (Íñiguez, 2008: 322). Finalmente, ha prevalecido la opción de retorno al sistema original de elección de los integrantes del sector judicial del Consejo.

25 El magistrado (antes fiscal) Carlos Lesmes fue dos veces director general en gobiernos del Partido Popular. Entrevistado en 2014 por el diario El Mundo, hizo esta afirmación estupefaciente: "Al juez se le controla con el palo y la zanahoria”. Repárese bien: el presidente de la más alta instancia jurisdiccional y presidente también del órgano de garantía de la independencia judicial, dispuesto a controlar de ese modo la actividad profesional consistente en decir el derecho con exclusiva sujeción a la ley.

26 La Ley Orgánica 2/2001 introdujo una reforma en el sistema electoral de los integrantes del CGPJ, para -buscando algún reforzamiento de su llamativa deslegitimación- dotarle, dice la Exposición de Motivos, de un consenso asentado sobre nuevas bases, implicando a las asociaciones judiciales y a los jueces no asociados en el proceso electoral, mediante la propuesta de candidatos a las cámaras. La medida ha quedado en la pura cosmética, desde luego en el caso de las asociaciones, que se limitan a oficiar de burocráticos cauces inertes, sin establecer relación alguna de representación con los asociados que lleguen al Consejo por esa vía. Es más, con la mayor frecuencia, esto ocurre porque el interesado cuenta ya, antes de presentarse como candidato, con el favor de un partido, que es ciertamente lo que importa.

27 No pudo ser más expresivo al respecto el titular del diario El País, de 10 de diciembre de 2012, uno de tantos: "Los vocales del Poder Judicial cumplen el pacto PP-PSOE y eligen a Lesmes" (habría sido más fiel a la realidad escribir votan). También el modo de rotular un editorial del mismo periódico, de 14 de noviembre de 2018: "Los partidos uuelven a intervenir en la elección de los vocales del Poder Judicial”, después de que se hubieran ido conociendo las negociaciones y también los nombres, incluido el del entonces pactado futuro presidente. 
el PSOE para la composición del futuro Consejo, escribía, dando cuenta de lo conseguido: "Ponemos a un presidente excepcional (...) además controlando la Sala Segunda desde detrás y presidiendo la sala 61 . Ha sido una jugada estupenda...”.

A mi juicio se trata de una intervención realmente importante por lo que expresa. No es solo una declaración de intenciones sino, especialmente, de principios, y evidencia toda una concepción corrupta y fuertemente anticonstitucional de la jurisdicción que, en este caso, preside además una estrategia; no imputable de manera exclusiva a Cosidó (que solo habría sido el remitente del mensaje), al tratarse de una concepción y de principios amplísimamente compartidos (al menos) dentro de su formación. Desde luego, por los 146 destinatarios del whatsapp - ¡la mayoría absoluta de la cámara!- a los que, si algo tan sucio podía serles comunicado y, además, ¡como un triunfo!, es porque compartían y tendrían motivo para celebrar esa "jugada estupenda”. El entusiasmo, es claro, tenía que ver con la situación procesal de ese partido, ya condenado por la Audiencia Nacional como partícipe a título lucrativo en actos de corrupción, y con no pocos de sus exponentes de relieve implicados en una infinidad de causas en trámite, que acabarán en la Sala Segunda del Tribunal Supremo, como se sabe, la competente para el conocimiento de procesos penales contra los aforados de mayor rango ${ }^{28}$.

Las vicisitudes de posible consideración en las que, a lo largo del tiempo, han ido plasmándose en las actuaciones (y omisiones) del Consejo, los negativos efectos del sistema de elección supuestamente parlamentaria, son innumerables. Esto impide realizar aquí un examen pormenorizado. Pero existe un tema-test, que es el más idóneo para ilustrar el modo de proceder en/con la institución. Me refiero a la política de nombramientos. Que informa fielmente sobre el concepto de independencia judicial y, en general, la clase de valores efectivamente profesados y promovidos durante decenios por el Consejo. Con escasos matices diferenciales en función del perfil político de la mayoría, y dejando siempre a salvo algunas -contadas-actitudes personales de calidad.

Una constante en la materia ha sido la ya histórica frecuente inobservancia, en los sucesivos mandatos, de los aludidos constitucionales principios de "mérito y capacidad", que deberían regir incondicionadamente. Porque son incontables las ocasiones en las que su lugar se ha visto ocupado por preferencias fundadas en el tráfico de diversas influencias, las relaciones de amistad, las filiaciones ideológicas y asociativas y otras de carácter, al fin, político. Es muy elocuente al respecto lo sucedido, durante este mandato, en relación con la Sala de lo Penal de la Audiencia Nacional, con los

28 El texto del whatsapp revela, además, con patente claridad, la estrategia que en esta ocasión (como seguramente en las anteriores y, por qué no, en las futuras) informó la actuación del Partido Popular en las negociaciones para renovación del Consejo. Lo que asimismo arroja luz acerca de la actitud mantenida por esta formación contra el magistrado de la Sala de lo Penal de la Audiencia Nacional, José Ricardo de Prada, un profesional ejemplar, injuriado y calumniado grauísimamente por altos exponentes de la misma, por haber cumplido con su deber constitucional en el juicio que concluyó con la sentencia condenatoria del PP como partícipe de delito a título lucrativo. Sentencia confirmada por el Tribunal Supremo. 
magistrados López y González ${ }^{29}$ y la magistrada Espejel. Los tres fueron recusados, con buen soporte de datos, por su bien conocida estrecha proximidad al Partido Popular, que les inhabilitaría para conocer con imparcialidad de las causas en las que este o algunos de sus exponentes estaban implicados. Las recusaciones resultaron estimadas por el pleno de aquel tribunal, quedando, por tanto, acreditada la directa relación con esa formación política de los tres magistrados, lo que, jurídica y, antes aún, deontológicamente, les habría obligado a abstenerse. Pues bien, de forma casi inmediata, fueron promocionados por el Consejo, no obstante tal gravísimo demérito, convertido así -de facto, contra legem y en fraude de Constitución- en ilegítimo mérito. Tanto que Espejel pasó a ser la presidenta de la Sala de lo Penal de la Audiencia Nacional, en la que están pendientes relevantes causas criminales que afectan intensamente al Partido Popular; González fue nombrado presidente de la Audiencia Provincial de Madrid; y López -actual consejero en el gobierno popular de la Comunidad de Madrid- seleccionado para formar parte de la nueva Sala de Apelaciones de la Audiencia Nacional ${ }^{30}$.

No creo que haga falta un gran esfuerzo de imaginación para representarse los demoledores efectos que esta clase de actuaciones han generado y generan en los integrantes de la magistratura española, a quienes el Consejo tendría que ofrecer la seguridad de una clara apuesta por el constitucional principio de independencia, dirigida a estimular su vigencia en las prácticas jurisdiccionales. Con la certeza para sus autores de que la calidad de estas en la materia sería, en todo caso, objeto de debida apreciación en el régimen de promociones. Algo que ha estado y está lejos de suceder.

Aunque parezca mentira, las vicisitudes expuestas son todavía insuficientes para ilustrar las patologías que asedian a esta desgraciada institución, con el inevitable demoledor efecto en la cultura y la práctica de la independencia judicial. Y es que, algo bien conocido, el actual mandato se encuentra anticonstitucional e ilegalmente prorrogado de facto (durante bastante más de dos años, en el momento de escribir estas páginas), debido el férreo obstruccionismo -y no es la primera vez- del Partido Popular. Con la también aberrante particularidad de que los veintiún integrantes del órgano que, con su dimisión, podrían haber evitado o puesto fin a tal perversa situación, permanecen anclados a sus puestos, avalando explícitamente cada día con su presencia lo que, puede decirse sin exageración, representa una suerte de golpe extra e intrainstitucional. Además, durante todo este tiempo, el Consejo, en semejante situación de gravísima ilegitimidad, ha realizado innumerables nombramientos de cargos judiciales.

29 Adscrito y mantenido en la Sala de lo Penal de la Audiencia Nacional en comisión de servicios, precisamente, para conocer de diversas piezas del caso Gürtel.

30 El nombramiento sería declarado nulo por el Tribunal Supremo debido a una deficiencia curricular, lo que no fue obstáculo para que este magistrado fuera ahora adscrito a la misma sala mediante nuevo acuerdo del Consejo, también declarado nulo por la alta instancia. Sorprendentemente, esto no impidió que el Consejo emitiera un nuevo acuerdo, ahora también en fraude de jurisdicción, volviendo a decidir en idéntico sentido. 
De semejante contexto forma parte la curiosa circunstancia de que el Partido Popular ha sido siempre pródigo en afirmaciones grandilocuentes en favor de la independencia judicial, autopresentándose como su gran valedor ${ }^{31}$. Aunque, ciertamente, hay que decir que ninguno de los dos grandes partidos (como tampoco los menores que se han sumado ocasionalmente a sus estrategias en el CGPJ), han dado pruebas de creer en ella y de asumirla efectivamente como valor. Más bien lo contrario. Algo, por lo demás, consecuente, en el marco de una política degradada que ha demostrado necesitar un significativo coeficiente de ilegalidad, para permanecer y reproducirse en sus constantes. Una política que, como se ha visto, lleva lustros filtrándose directamente en la judicial del Consejo, sin apenas mediaciones.

Las vicisitudes reseñadas, como la infinidad de otras relacionadas con este que podrían sumarse, es obvio, se han dado con las peores consecuencias para la cultura constitucional de la independencia y de la jurisdicción de los jueces españoles. En efecto, pues lo producido ha sido más bien una persistente difusión de contravalores en la materia. Un buen indicador al respecto es que jamás un juez o tribunal vilipendiado ante la opinión a causa de una resolución irreprochable pero incómoda para algún sujeto de poder, ha obtenido del Consejo la defensa que merecía.

En España, por fortuna, los jueces y tribunales gozan de un estatuto de independencia, mejorable, pero razonablemente garantizado en el plano normativo y, seguramente, con traducción efectiva en la inmensa mayoría de sus prácticas. Ahora bien, este hecho es, en esencia, fruto exclusivo del personal compromiso de cada uno de aquellos con la función jurisdiccional. En efecto, porque - ¡cuesta escribirlo!- no debe nada al Consejo General del Poder Judicial, tan catastróficamente frustrado en su papel de órgano independiente de garantía de los valores de la jurisdicción. 


\section{BIBLIOGRAFÍA}

Althusser, L. (1968). Montesquieu, la política y la historia. Trad. cast. de M. E. Benítez. Madrid: Ciencia Nueva.

Anderson, P. (1979). Transiciones de la antigüedad al feudalismo. Trad. cast. de S. Juliá. Madrid: Siglo XXI.

Andrés, P. y Mouilla, C. (1986). El poder judicial. Madrid: Tecnos.

Andrés, P. (2015). Tercero en discordia. Jurisdicción y juez en el estado constitucional. Madrid: Trotta.

Andrés, P. (2018). Preconstitución legal del juez: un principio en espera de [rigurosa] aplicación. Jueces para la Democracia. Información y debate, 91, 5-21.

Battaglia, A. (1962). I giudici e la política. Bari: Laterza.

Beccaria, C. (2011). De los delitos y de las penas. Edición bilingüe, texto italiano fijado por G. Francioni, trad. cast. de F. Laplaza, edición al cuidado de P. Andrés Ibáñez, con prólogo de P. Calamandrei. Madrid: Trotta.

Bonasi, A. (1884). La magistratura in Italia. Bologna: Nicola Zanichelli.

Calamandrei, P. (1960). Proceso y democracia. Trad. cast. de H. Fix Zamudio. Buenos Aires: Ediciones Jurídicas Europa-América.

Casamayor (1957). Les juges. Paris: Editions du Seuil.

Fernández-Crehuet, F. (2011). Jueces bajo el franquismo. Once historias (y una nota sobre la depuración de los funcionaros judiciales). Granada: Comares.
Ferrajoli, L. (2011). Principia iuris. Teoría del derecho y de la democracia, I Teoría del derecho. Trad. cast. de P. Andrés Ibáñez, J. C. Bayón, M. Gascón, L. Prieto y A. Ruiz Miguel. Madrid: Trotta.

García Pelayo, M. (1968). Del mito y de la razón en el pensamiento político. (Estudio sobre las formas políticas de la Edad Media). Madrid: Revista de Occidente.

Guarnieri, C. (1997). Magistratura e sistema político nella storia d'Italia. En R. Romanelli (Ed.). Magistratura e potere, (pp. 241 y ss.). Bologna: II Mulino.

Hamilton, A., Madison, J. y Jay, J. (1957). El Federalista. Prólogo y traducción de G. T. Velasco, $2^{a}$ edición. Ciudad de México: Fondo de Cultura Económica.

Hilbink, L. (2014). Jueces y política en democracia y dictadura. Lecciones desde Chile. Trad. cast. de F. Millán Zapata. Ciudad de México: FLACSO, México.

Íñiguez, D. (2008). El fracaso del autogobierno judicial. Madrid: Fundación Alfonso Martín Escudero; Cizur Menor (Navarra): Civitas.

Kantorowicz, E. H. (2012). Los dos cuerpos del rey. Un estudio de teología política medieval. Trad. cast. de S. Aikin Araluce y R. Blázquez Godoy, con prólogo de W. Chester Jordan y estudio preliminar de J. M. Nieto Soria. Madrid: Akal.

Kelsen, H. (2003). La paz por medio del derecho. Trad. cast. de L. Echávarri, introducción de M. La Torre y C. García Pascual. Madrid: Trotta.

Lanero Táboas, M. (1996). Una milicia de la justicia. La política judicial del franquismo (1936-1945). Madrid: Centro de Estudios Constitucionales.

Lefebure, E. (1977). De l'etat. 3. Le mode de production étatique. Paris: Union Générale d'Editions. 
Mannori, L. (1997). Giustizia e amministrazione tra antico e nuovo regime. En R. Romanelli (Ed.). Magistratura e potere nella storia europea, (pp. 39 y ss.). Bologna: Il Mulino.

Matus Acuña, A. (2000). El libro negro de la justicia chilena. Barcelona: Planeta.

Montesquieu, Ch. (1972). Del espíritu de las leyes. Trad. cast. de M. Blázquez y P. de Vega, prólogo de E. tierno Galuán. Madrid: Tecnos.

Muratori, L. (1794). Defectos de la jurisprudencia. Trad. cast. de V. M. de Tercilla. Madrid: Imprenta de la viuda de D. Joachin Ibarra.

Müller, I. (2009). Los juristas del horror. La "justicia" de Hitler: el pasado que Alemania no puede dejar atrás. Trad. cast. de C. Armando Figueredo, prólogo a esta edición de E. Casanoua. Bogotá. Colombia: Áluaro Nora Librería Jurídica.

Murena, M. (1785). Tratado sobe las obligaciones del juez. Trad. cast., (de la edición francesa) de C. Cladera. Madrid: Plácido Barco López.

Pardo, M. (2009). Magistratura profesional. Valencia: Tirant lo Blanch; Murcia: Editum, Ediciones de la Universidad de Murcia.
Pizzorusso, A. (1984). Il Consiglio Superiore della Magistratura nella forma di governo vigente in Italia. Questione Giustizia, 3, 281-306.

Pizzorusso, A. (1990). L'organizzazione della giustizia in Italia. Torino: Einaudi.

Portilla Contreras, G. (2019). Derecho penal franquista y represión de la homosexualidad. Madrid: Ministerio de Justicia.

Pound, R. (1954). El espíritu del 'common law'. Trad. cast. de J. Puig Brutau. Barcelona: Bosch.

Royer, J. P. (1995). Histoire de la justice en France. Paris: Presses Universitaires de France.

Saita, R. (1975). Costituenti e costituzioni della Francia rivoluzionaria e liberale (1789-1785).

Milano: Giuffrè.

Silvestri, G. (1979). La separazione dei poteri, vol. I. Milano: Giuffré.

Varaut, J. M. (2004). Indépendance. En L. Cadier (Dir.). Dictionaire de la justice. Paris: Presses Universitaires de France.

Zagrebelsky, G. (1982). La responsabilità del magistrato nell'attuale ordinamento. Prospettive di reforma. Giurisprudenza costituzionale, 1, 780-795. 